\title{
Identification of inhibitors of Plasmodium falciparum phosphoethanolamine methyltransferase using an enzyme-coupled transmethylation assay
}

April M Bobenchik ${ }^{1,2}$, Jae-Yeon Choi ${ }^{3}$, Arunima Mishra ${ }^{2}$, Iulian N Rujan ${ }^{4}$, Bing Hao ${ }^{4}$, Dennis R Voelker ${ }^{3}$, Jeffrey $\mathrm{CHoch}^{4}$, Choukri Ben Mamoun ${ }^{1 *}$

\begin{abstract}
Background: The phosphoethanolamine methyltransferase, PfPMT, of the human malaria parasite Plasmodium falciparum, a member of a newly identified family of phosphoethanolamine methyltransferases (PMT) found solely in some protozoa, nematodes, frogs, and plants, is involved in the synthesis of the major membrane phospholipid, phosphatidylcholine. PMT enzymes catalyze a three-step S-adenosylmethionine-dependent methylation of the nitrogen atom of phosphoethanolamine to form phosphocholine. In $P$. falciparum, this activity is a limiting step in the pathway of synthesis of phosphatidylcholine from serine and plays an important role in the development, replication and survival of the parasite within human red blood cells.
\end{abstract}

Results: We have employed an enzyme-coupled methylation assay to screen for potential inhibitors of PfPMT. In addition to hexadecyltrimethylammonium, previously known to inhibit PfPMT, two compounds dodecyltrimethylammonium and amodiaquine were also found to inhibit PFPMT activity in vitro. Interestingly, PfPMT activity was not inhibited by the amodiaquine analog, chloroquine, or other aminoquinolines, amino alcohols, or histamine methyltransferase inhibitors. Using yeast as a surrogate system we found that unlike wildtype cells, yeast mutants that rely on PfPMT for survival were sensitive to amodiaquine, and their phosphatidylcholine biosynthesis was inhibited by this compound. Furthermore NMR titration studies to characterize the interaction between amoidaquine and PfPMT demonstrated a specific and concentration dependent binding of the compound to the enzyme.

Conclusion: The identification of amodiaquine as an inhibitor of PfPMT in vitro and in yeast, and the biophysical evidence for the specific interaction of the compound with the enzyme will set the stage for the development of analogs of this drug that specifically inhibit this enzyme and possibly other PMTs.

\section{Background}

Malaria is one of the most important parasitic diseases worldwide responsible for over 200 million clinical cases with an estimated 1 million deaths annually [1]. Malaria is caused by intraerythrocytic protozoan parasites of the genus Plasmodium. Of the five species infective to humans, Plasmodium falciparum is responsible for the highest level of mortality and morbidity [1]. The lack of

\footnotetext{
* Correspondence: choukri.benmamoun@yale.edu

'Department of Internal Medicine, Section of Infectious Diseases, Yale School
} of Medicine, 333 Cedar St., New Haven, 06052, USA an effective vaccine and the rapid rise of resistance to the most potent and affordable antimalarial drugs creates an urgent need for new therapies to prevent malaria pathogenesis and transmission. Novel strategies are now necessary to limit the appearance and spread of drug resistant malaria strains. One such a strategy involves targeting metabolic pathways proven to play an essential function in the parasite's infection and transmission. Recent studies indicate that the metabolic pathways for the synthesis of the major $P$. falciparum phospholipids are excellent targets for the development of lipid-based antimalarial therapies [2-4].

\section{C) Biomed Central}


Studies in P. falciparum demonstrated that the synthesis of phosphatidylcholine during the intraerythrocytic life cycle of the parasite occurs via two pathways, the serine-decarboxylase phosphoethanolemine methyltransferase (SDPM) pathway and the CDP-choline pathway [2-4]. The SDPM pathway uses serine either transported from human serum or resulting from degradation of host hemoglobin as a starting precursor. Serine is first decarboxylated by a parasite serine decarboxylase to form ethanolamine. Ethanolamine is next phosphorylated by a parasite ethanolamine kinase to form phosphoethanolamine (P-EA). A parasite Sadenosylmethionine (SAM)-dependent methyltransferase, PfPMT, catalyzes a three-step methylation of P-EA to form phosphocholine $[3,5,6]$, which is converted into phosphatidylcholine (PtdCho) via the activity of two parasite enzymes PfCCT and PfCEPT. The CDP-choline pathway uses choline transported from the host as a precursor. Choline is phosphorylated by a parasite choline kinase PfCK to phosphocholine, which is subsequently modified by PfCCT to CDP-choline and by PfCEPT to PtdCho.

The 266 amino acid PfPMT is a member of a new class of SAM-dependent methyltransferases that acts on P-EA [3]. Homologs of this enzyme are found in plants, nematodes, frogs, fish and other protozoa but not in mammals [7-11]. While phosphoethanolamine methyltransferases (PEAMT) share significant homology in their primary structure, the organization of their catalytic domains differ. The plant PEAMTs have two tandem catalytic domains, with the N-terminal domain catalyzing the methylation of P-EA to monomethylphosphoethanolamine and the $\mathrm{C}$-terminal domain acting in the last two methylation reactions to form phosphocholine $[7,9,10]$. C. elegans expresses two PEAMT enzymes each containing only one methyltransferase domain located at either the $\mathrm{N}$-terminus of the protein, in the case of Pmt1, or at the C-terminus of the protein in Pmt2 [8,11]. Pmt1 catalyzes only the first methylation reaction, whereas Pmt2 catalyzes the last two methylation reactions. The Plasmodium PfPMT is only half the size of the plant and nematode proteins, possesses a single catalytic domain, and catalyzes all three methylation steps [3]. No crystal or solution structures of these enzymes are available.

Confocal and immunoelectron microscopy studies have shown that PfPMT is expressed in the Golgi apparatus of the parasite [12]. Biochemical and genetic analyses using yeast as a surrogate system allowed identification of residues in this enzyme that play a critical role in PfPMT catalysis and substrate binding [6]. The finding that PfPMT has no homologs in mammalian databases suggested that this protein could be an ideal target for the development of novel antimalarial inhibitors targeting lipid metabolism. Interestingly, biochemical studies revealed that PfPMT activity was inhibited by $\mathrm{S}$-adenosyl homocysteine $(\mathrm{SAH})$ as well as by phosphocholine and its analog and anticancer drug, hexadecylphosphocholine (Miltefosine) [3]. When tested against $P$. falciparum, hexadecylphosphocholine was found to inhibit the growth of the parasite within human erythrocytes with $50 \%$ inhibitory concentrations in the low micromolar range [3]. Genetic studies in $P$. falciparum demonstrated that PfPMT plays an important role during the intraerythrocytic life cycle of the parasite [13]. Parasites lacking PfPMT display severe alterations in development, replication and survival within human red blood cells [13]. These defects were only partially complemented by choline supplementation.

Here we provide biochemical and biophysical data indicating that PfPMT activity is inhibited by amodiaquine (AQ). Using yeast as a surrogate system we show that AQ inhibits PfPMT activity and blocks PtdCho biosynthesis.

\section{Methods}

\section{Materials}

S-adenosylmethionine (SAM), S-adenosylhomocysteine (SAH), Phosphoethanolamine (P-Etn), Cholorquine (CQ), Amodiaquine (AQ), Hexadecyltrimethylammonium bromide (HDTA), Dodecyltrimethylammonium bromide (DDTA), 2,3-Dichloro- a- methylbenzylamine (DCMB), Chlorpromazine, and Diphenhydramine were purchased from Sigma. Miltefosine (HePC) was purchased from Cayman chemicals. SKF91488 and Tacrine were purchased from Tocris Bioscience. Recombinant SAH nucleosidase (SAHN) was purified from an E. coli strain generously given by K. Cornell (VAMC, Portland, OR, USA), as previously described [14].

\section{Expression and purification of recombinant PfPMT and BsAda}

$P$. falciparum PfPMT cDNA cloned in the expression vector $\mathrm{pET}-15 \mathrm{~b}$ and expressed in E. coli BL21-CodonPlus strain was purified as described earlier $[3,6]$. Expression strains were grown at $37^{\circ} \mathrm{C}$ in $\mathrm{LB}$ medium containing $100 \mu \mathrm{g} / \mathrm{ml}$ ampicillin and $35 \mu \mathrm{g} / \mathrm{ml}$ chloramphenicol. A $1 \mathrm{~L}$ culture of $E$. coli was grown until an $\mathrm{A}_{600} \sim 0.6$, and PfPMT expression was induced by addition of $1 \mathrm{mM}$ isopropyl- $\beta$-D-thiogalactopyranosidase (IPTG). The cells were harvested $3 \mathrm{~h}$ after induction by centrifugation, and resuspended in $25 \mathrm{ml}$ lysis buffer (50 $\mathrm{mM} \mathrm{NaH} \mathrm{PO}_{4}, 300 \mathrm{mM} \mathrm{NaCl}, 10 \mathrm{mM}$ imidazole, $\mathrm{pH}$ 8.0) containing a protease inhibitor cocktail (complete Mini, EDTA-free, Roche Diagnostics). The cells were lysed by sonication using $10 \mathrm{~s}$ discontinuous cycles for three minutes on ice, and the cell debris and unbroken cells were removed by centrifugation at $10,000 \mathrm{rpm}$ at 
$4^{\circ} \mathrm{C}$ for $30 \mathrm{~min}$. The supernatant was directly applied to a $5 \mathrm{ml} \mathrm{Ni-NTA} \mathrm{(Qiagen)} \mathrm{column} \mathrm{pre-equilibrated} \mathrm{in}$ lysis buffer. The column was subsequently washed with $40 \mathrm{ml}$ of buffer $\left(50 \mathrm{mM} \mathrm{NaH} \mathrm{PO}_{4}, 300 \mathrm{mM} \mathrm{NaCl}, 20\right.$ $\mathrm{mM}$ imidazole, $\mathrm{pH} 8.0$ ) and the protein was eluted from the column in a single $15 \mathrm{ml}$ fraction of buffer $(50 \mathrm{mM}$ $\mathrm{NaH}_{2} \mathrm{PO}_{4}, 300 \mathrm{mM} \mathrm{NaCl}, 250 \mathrm{mM}$ imidazole, $\mathrm{pH}$ 8.0). The protein was incubated at $4^{\circ} \mathrm{C}$ for $1 \mathrm{~h}$ in the presence of $2 \mathrm{mM} \mathrm{Na}{ }_{2}$ EDTA, followed by dialysis and concentration against HEPES (N-(2-hydroxyethyl)piperazine-N'-2-ethanesulfonic acid) assay buffer (100 mM HEPES-KOH, pH 7.5) using Amicon Ultra centrifugal filter devices. The purity of the recombinant enzyme was examined by SDS-PAGE, and the protein concentration was measured by the method of Bradford using bovine serum albumin as a standard.

The gene encoding Bacillus subtilis adenine deaminase (BsAda) was amplified from genomic DNA by PCR and ligated into a pET15b plasmid vector between XhoI and BamHI sites to yield an N-terminal 6His-epitope-tagged encoding construct. The resulting plasmid was then transformed into E. coli BL21-CodonPlus strain for enzyme expression. The purification protocol for BsAda is similar to PfPMT purification except that the $1 \mathrm{hr}$ incubation step with $2 \mathrm{mM} \mathrm{Na} \mathrm{m}_{2}$ EDTA was omitted.

\section{PfPMT enzyme-coupled spectrophotometric assay}

Assays were performed in 96-well UV-transparent plates (acrylic, non-sterile, Costar) at $37^{\circ} \mathrm{C}$. Manganese sulfate (MnSO4) was added to a final concentration of $1 \mathrm{mM}$ [15]. The assay mixture in $1 \mathrm{X}$ HEPES assay buffer (100 $\mathrm{mM}$ HEPES-KOH, pH 7.5) contained $200 \mu \mathrm{M}$ SAM, $200 \mu \mathrm{M}$ P-EA, $1 \mathrm{mM}$ MnSO4, $0.5 \mu \mathrm{M}$ BsAda, $4.72 \mu \mathrm{M}$ SAHN and $2.5 \mu \mathrm{M}$ PfPMT in a total volume of $200 \mu \mathrm{l}$. A mixture without PfPMT was pre-incubated at $37^{\circ} \mathrm{C}$ for $10 \mathrm{~min}$ and the reaction was initiated with the addition of PfPMT. Absorbance at $265 \mathrm{~nm}$ was continuously recorded with a UV, visible plate-reader (Synergy HT Multi-Mode Microplate Reader, Biotek) under kinetic mode. A negative control containing all the reaction components except for PfPMT was conducted on the same plate as the experimental reactions. The absorbance value of the control reaction was subtracted from the experimental absorbance values to eliminate the background signal.

\section{Inhibition studies}

All inhibitor containing stock solutions were prepared in $\mathrm{H}_{2} \mathrm{O}$, except for HDTA, which was prepared in DMSO. The final concentration of DMSO in the assays did not exceed $10 \%$. Control experiments containing reaction components and inhibitors were performed in the absence of PfPMT to quantify the intrinsic absorbance of inhibitors at $265 \mathrm{~nm}$. These inhibitors were added before the pre-incubation step. The absorbance at 265 $\mathrm{nm}$ for a PfPMT assay without inhibitor was assigned as
100\% PfPMT activity. The absorbance values obtained for the various inhibitor concentrations were then converted into a PfPMT activity percentage and plotted against inhibitor concentration. Control experiments were performed to ensure that the inhibitors did not affect the coupling enzymes. To measure coupling enzyme sensitivity to inhibitors, $100 \mu \mathrm{M}$ SAH was used in place of SAM and P-EA in a $200 \mu$ reaction in the presence of the inhibitor at the highest concentration used in PfPMT assay. For Ki determination enzymatic assays were performed with increasing concentrations of P-EA (50, 75, 100, 125, 150, 175, and $200 \mu \mathrm{M}), 200 \mu \mathrm{M}$ SAM, $1 \mathrm{mM} \mathrm{MnSO} 4,0.5 \mu \mathrm{M}$ BsAda, $4.72 \mu \mathrm{M}$ SAHN and $2.5 \mu \mathrm{M}$ PfPMT in a HEPES assay buffer, along with the inhibitor AQ $(0,2,4,10 \mu \mathrm{M})$. A reciprocal plot was generated from the absorbance readings at $265 \mathrm{~nm}$ versus the P-EA concentrations for each concentration of $A Q$. The fitted line was extrapolated through the $\mathrm{X}$ axis to determine the estimated $\mathrm{Ki}$.

\section{Yeast growth assays}

BY4741-pYes2.1 (wild-type) and mutant pem1 1 pem2 2 pYes2.1-PfPMT yeast strains were pre-grown overnight in uracil dropout synthetic galactose (4\%) (SG-ura) medium supplemented with $10 \mu \mathrm{M}$ ethanolamine. The next day, cells were harvested by centrifugation, washed twice by resuspension in water and diluted to an $\mathrm{A}_{600}=0.005$ in fresh SG-ura medium supplemented with $100 \mu \mathrm{M}$ ethanolamine, in the absence or presence of 10,50 , or $100 \mu \mathrm{M} A Q$. In a second set of experiments BY4741-

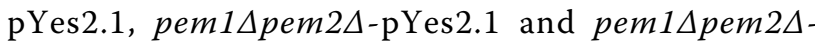
pYes2.1-PfPMT yeast strains were pre-grown overnight in SG-ura medium supplemented with $2 \mathrm{mM}$ ethanolamine. The next day, cells were harvested by centrifugation, washed by resuspension in water and diluted to an $\mathrm{A}_{600}=0.005$ in fresh SG-ura medium lacking or supplemented with $1 \mathrm{mM}$ choline in the presence of 0 or 200 $\mu \mathrm{M} A \mathrm{AQ}$. In both sets of experiments, cells were grown at $30^{\circ} \mathrm{C}$ and monitored by measuring the $\mathrm{A}_{600}$.

\section{Yeast phospholipid analysis}

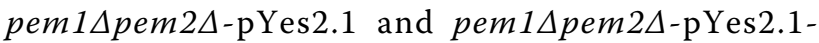
PfPMT yeast strains were pre-grown in SG-ura medium supplemented with $2 \mathrm{mM}$ ethanolamine and 2 $\mathrm{mM}$ choline for 24 hours. The cells were harvested by centrifugation, washed twice by resuspension in water and diluted to an $\mathrm{A}_{600}=0.03$ in the SG-ura medium supplemented with $2 \mathrm{mM}$ ethanolamine and grown overnight to an $\mathrm{A}_{600} \sim 1.5$. The cells were next harvested and the lipids extracted for two dimensional thin layer chromatography using previously described methods $[5,6,16]$. Lipids were stained with iodine vapor and excised from the plate for quantification by measuring phosphorus [17]. The results are shown as the percentage of total phosphorus in each phospholipid fraction. 


\section{NMR experiments}

For NMR analysis, E. coli cells expressing 6his-epitopetagged PfPMT were grown in minimal medium (M9) containing ${ }^{15} \mathrm{~N}$-ammonium chloride. The purification of the recombinant enzyme followed the same procedure described above except for the addition of a second step of purification through a Superdex G75 gel filtration column in a buffer containing $50 \mathrm{mM}$ HEPES, 50 $\mathrm{mM} \mathrm{NaCl}, 5 \mathrm{mM}$ DTT pH 6.9. The sample was concentrated and $\mathrm{D}_{2} \mathrm{O}$ was added to a final concentration of $7 \%(\mathrm{v} / \mathrm{v})$. Amodiaquine stock solution was prepared in $\mathrm{dd}_{2} \mathrm{O}$ due to its low solubility. Serial dilutions were prepared and $5 \mu \mathrm{l}$ of the diluted samples were added to the NMR sample containing $310 \mu \mathrm{M}$ of purified PfPMT. The AQ concentration was determined spectrophotometrically using extinction coefficients $\varepsilon_{238}=27 \times 10^{3} \mathrm{M}^{-}$ ${ }^{1} \mathrm{~cm}^{-1}, \varepsilon_{251}=23 \times 10^{3} \mathrm{M}^{-1} \mathrm{~cm}^{-1}$ and $\varepsilon_{341}=19 \times 10^{3} \mathrm{M}^{-}$ ${ }^{1} \mathrm{~cm}^{-1}$ [18]. The PfPMT concentration was determined using the Edelhoch method [19-21]. Standard ${ }^{1} \mathrm{H}_{-}{ }^{15} \mathrm{~N}$ HSQC experiments were performed on ${ }^{15} \mathrm{~N}$-labeled PfPMT using a Varian Inova spectrometer operating at a ${ }^{1} \mathrm{H}$ frequency of $600 \mathrm{MHz}$. Data were processed using nmrPipe [22] and analyzed using Sparky [23] or the Rowland NMR Toolkit http://rnmrtk.uchc.edu.

\section{Results}

\section{Coupling PfPMT activity to that of SAH nucleosidase and adenine deaminase}

To identify new inhibitors of PfPMT we adapted an assay that couples the SAM-dependent transmethylation of P-EA by PfPMT to the activity of two enzymes SAH nucleosidase (SAHN) and adenine deaminase (BsAda) (Fig. 1). PfPMT activity results in the production of SAH and phosphocholine. The second enzyme SAHN catalyzes the conversion of SAH into adenine and Sribosylhomocysteine. Adenine is converted into hypoxanthine by the third enzyme, BsAda, thus producing a decrease in absorbance at $265 \mathrm{~nm}$ (Fig. 2A). As shown in Fig. 2A, addition of PfPMT resulted in a time-dependent decrease in absorbance at $265 \mathrm{~nm}$ over a $30 \mathrm{~min}$ period, whereas no change in absorbance occurred when the enzyme was omitted. To demonstrate that the measured rate of the coupled reactions was determined solely by PfPMT, the enzyme activity was investigated in the presence of a fixed PfPMT concentration but with varying concentrations of SAHN or BsAda. As shown in Fig. 2B, changing the concentrations of the coupling enzymes had little or no effect on the overall rate of the reactions. The effect of increasing concentrations of the substrate P-EA and co-substrate SAM on PfPMT activity was also measured. PfPMT activity increased proportionally to the concentration of these substrates, with optimal activity measured when the substrate and cosubstrate concentrations were at $200 \mu \mathrm{M}$ (Fig. 2C).
Higher concentrations of P-EA only slightly affected the activity of the enzyme, whereas high SAM concentrations inhibited the enzyme (data not shown). Under optimal conditions, we also examined the effect of PfPMT concentration on the rate of the reaction. As shown in Fig. 2D, increasing the concentration of PfPMT resulted in a proportional increase in activity reflected by a decrease in absorbance over time. Above this range, the enzyme activity started to deviate from linearity (data not shown). We also tested the effect of different buffers at $\mathrm{pH} 7,7.5$ and 8 on PfPMT activity. These factors were found to have little effect on PfPMT activity over time (Fig. 2E).

\section{Application of the PfPMT spectrophotometric assay for screening inhibitors of the enzyme}

To assess the applicability of the enzyme-coupled assay for screening inhibitors of PfPMT, the effects of some known or potential inhibitors of this enzyme were examined. As most drug screens are performed in the presence of DMSO, we first tested the effect of this agent on PfPMT activity. DMSO up to $10 \%$ had no effect on PfPMT activity (data not shown). The hexadecylphosphocholine analog, miltefosine (HePC), was previously reported to inhibit PfPMT activity in vitro and $P$. falciparum proliferation inside red blood cells with similar efficacy [3]. Using the enzyme-coupled spectrophotometric assay, HePC was found to inhibit PfPMT activity with $100 \mu \mathrm{M}$ of $\mathrm{HePC}$ reducing PfPMT activity by $\sim 60 \%$ and $150 \mu \mathrm{M}$ of the compound resulting in a complete loss of activity (Fig. 3A). As a control, an assay in which PfPMT, SAM and P-EA were omitted and replaced by their product $\mathrm{SAH}$ was performed in the absence or presence of $200 \mu \mathrm{M}$ of HePC. Under these conditions $\mathrm{HePC}$ had no effect on the production of hypoxanthine over time, suggesting that neither SAHN nor BsAda was inhibited by this compound. Two compounds that are structurally related to HePC, hexadecyltrimethylammonium (HDTA) and dodecyltrimethylammonium (DDTA) that are known to have potent antimalarial activity in vitro and in vivo [24-26] were also tested to determine their inhibitory activity against PfPMT. HDTA was found to have an inhibitory activity similar to that of $\mathrm{HePC}$ with $\sim 50 \%$ inhibition of PfPMT activity observed at $100 \mu \mathrm{M}$ of the compound (Fig. 3B). DDTA, however, had no effect against the enzyme when used at concentrations of up to $100 \mu \mathrm{M}$ and only modest inhibitory activity at 500 $\mu \mathrm{M}$, inhibiting $25 \%$ of PfPMT activity at this concentration (Fig. 3C).

Inhibition of PfPMT activity by amodiaquine in vitro and in yeast

In order to identify possible lead inhibitors of PfPMT, we examined the effect of drugs known to inhibit other SAM-dependent methyltransferases. The 2,3-dichloro- 


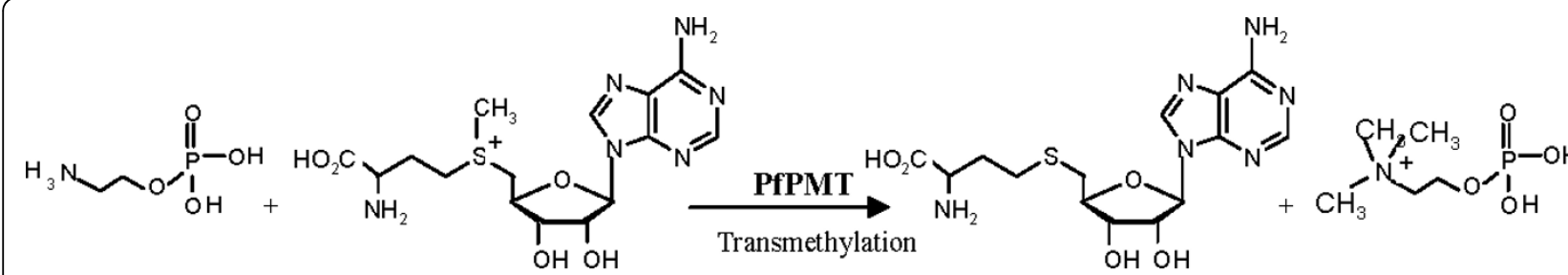

Phosphoethanolamine (1x)
S-Adenosylmethionine (SAM)

(3x)
S-Adenosylhomocysteine (SAH)

(3x)
Phosphocholine

(1x)

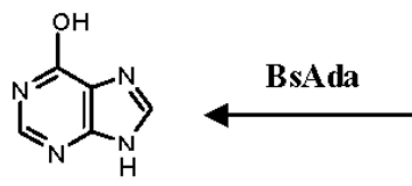

Hypoxanthine

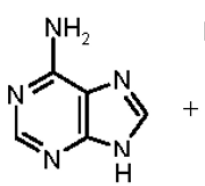

Adenine

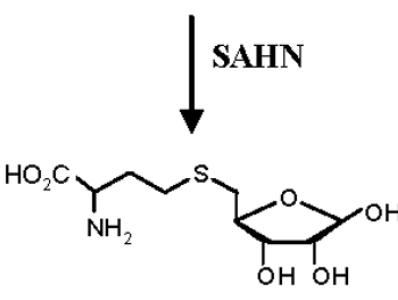

S-Ribosylhomocysteine

Figure 1 Schematic description of the enzyme-coupled assay for measuring PfPMT activity. PfPMT catalyzes the conversion of 1 molecule of P-EA and 3 molecules of SAM to form 1 molecule of phosphocholine and 3 molecules of SAH. SAH is hydrolyzed to adenine and Sribosylhomocysteine via SAHN nucleosidase. The deamination of adenine into hypoxanthine by adenine deaminase is associated with a decrease in absorbance at $265 \mathrm{~nm}$ that can be monitored continuously using UV plate reader.

methylbenzyl-amine (DCMB), a known inhibitor of the human phenylethanolamine- $\mathrm{N}$-methyltransferase enzyme [27], which catalyses the terminal step in epinephrine biosynthesis had no effect on PfPMT activity even at $500 \mu \mathrm{M}$ (Fig. 4A). Conversely, AQ, a known inhibitor of histamine methyltransferases (HNMT) and a potent antimalarial drug [28], was found to be a good inhibitor of the enzyme with $60 \%$ inhibition at $5 \mu \mathrm{M}$ (Fig. 4B). None of these concentrations of AQ inhibited the coupling enzymes used in the PfPMT assay (data not shown). The finding that AQ inhibits PfPMT led us to investigate the effect of four other HNMT inhibitors, SKF91488, Tacrine, Chlorpromazine and Diphenhydramine. None of these compounds had a significant effect on PfPMT activity (Fig. 5A). Furthermore, none of the compounds inhibited the growth of $P$. falciparum within human erythrocytes at a concentration as high as $1 \mu \mathrm{M}$ (data not shown). The specificity of inhibition of PfPMT by AQ was further demonstrated using its analog and antimalarial drug, chloroquine (CQ). At $200 \mu \mathrm{M}$ concentration, CQ had no effect on PfPMT activity (Fig. $5 \mathrm{~B})$. Other aminoquinolines and amino alcohols, quinacrine, quinidine and quinine, known for their potent antimalarial activity, had no effect on PfPMT activity at concentrations up to $200 \mu \mathrm{M}$ (Fig. 5B), suggesting that $A Q$ inhibition of PfPMT is specific. In order to examine AQ inhibition of PfPMT in vivo we used yeast as a surrogate system. Yeast is a particularly attractive system for this analysis because, unlike $P$. falciparum, it is not sensitive to AQ and lacks phosphoethanolamine methyltransferases. We have previously shown that a codonoptimized P. falciparum PfPMT gene complements the choline auxotrophy of the yeast pem $1 \Delta$ pem $2 \Delta$ mutant, which lacks the two phospholipid methyltransferases, Pem1p and Pem2p, and thus is unable to synthesize PtdCho from PtdEtn [29,30]. In the complemented strain, PfPMT restores PtdCho by providing phosphocholine following P-EA transmethylation [5,6]. Examination of the growth of wild-type yeast cells in media lacking or containing choline, and supplemented with either $100 \mu \mathrm{M}$ or $2 \mu \mathrm{M}$ ethanolamine (Fig. $6 \mathrm{~A}$ and $6 \mathrm{C}$ ), and in the absence or presence of $\mathrm{AQ}$ demonstrated no effect of this compound at concentrations up to 200 $\mu \mathrm{M}$. Unlike pem1 1 pem $2 \Delta$, which did not grow on medium containing ethanolamine but lacking choline (Fig. $6 \mathrm{D}$, curve $5 \& 6$ ), pem $1 \Delta$ pem $2 \Delta$ strains complemented with PfPMT grew on media lacking choline and their growth rate was significantly influenced by the availability of ethanolamine with the highest cell density reached in the presence of $2 \mu \mathrm{M}$ ethanolamine (Fig 6E, curve 5 \& 6). Interestingly, the growth of pem $1 \Delta$ pem $2 \Delta+\mathrm{PfPMT}$ was dramatically inhibited when $A Q$ was added to the culture medium (Fig. 6B). AQ inhibited the growth of pem $1 \Delta$ pem $2 \Delta+$ PfPMT strains in a concentration 

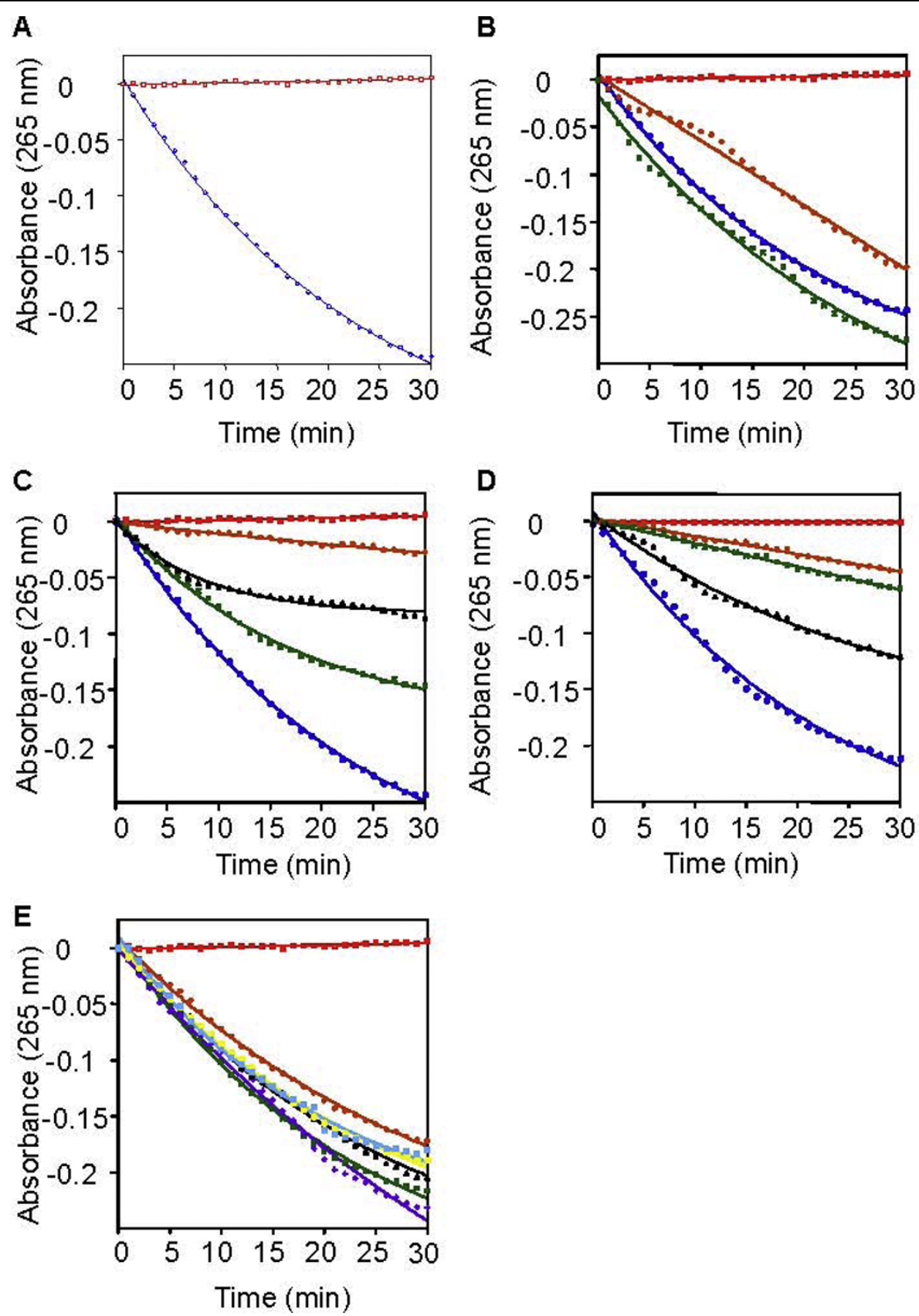

Figure 2 Spectrophotometric analysis of phosphoethanolamine methyltransferase activity. (A) PfPMT-catalyzed methylation of P-EA. Reaction mixtures contained $200 \mu \mathrm{M}$ SAM, $200 \mu \mathrm{M}$ P-EA, $1000 \mu \mathrm{M} \mathrm{MnSO}_{4}, 0.5 \mu \mathrm{M}$ BsAda, $4.72 \mu \mathrm{M}$ SAHN and $0 \mu \mathrm{M}$ (red) or $2.5 \mu \mathrm{M}$ (blue) of purified PfPMT enzyme in $100 \mathrm{mM}$ HEPES assay buffer $\mathrm{pH}$ 7.5. The decrease in absorbance was monitored at $265 \mathrm{~nm}$. The reactions components were kept the same as stated above in panels B-E, except when noted. (B) Dependence of the rate of PfPMT-catalyzed reaction on different concentrations of the coupling enzymes. Reactions contained BsAda $0.25 \mu \mathrm{M}$ and SAHN $2.13 \mu \mathrm{M}$ (orange), $0.5 \mu \mathrm{M}$ BsAda, $4.72 \mu \mathrm{M}$ SAHN (blue) and without PfPMT (red), and BsAda $1 \mu \mathrm{M}$ and SAHN $8.5 \mu \mathrm{M}$ (green). (C) Dependence of the rate of PfPMT-catalyzed reaction on different concentrations of SAM and P-EA. Reactions contained P-EA $50 \mu \mathrm{M}$ and SAM $150 \mu \mathrm{M}$ (orange), P-EA $100 \mu \mathrm{M}$ and SAM $100 \mu \mathrm{M}$ (black), p-Etn 150 $\mu M$ and SAM $150 \mu M$ (green), P-EA $200 \mu M$ and SAM $200 \mu M$ (blue), and without PfPMT (red). (D) Effect of PfPMT concentration on its activity. Reactions contained $0 \mu \mathrm{M}$ PfPMT (red), $312.5 \mathrm{nM}$ PfPMT (orange), $625 \mathrm{nM}$ PfPMT (green), $1.25 \mu \mathrm{M}$ PfPMT (black), and $2.5 \mu \mathrm{M}$ (blue). (E) Effect of the $\mathrm{pH}$ and buffer composition on PfPMT activity. Reaction mixtures contained $200 \mu \mathrm{M} \mathrm{SAM}, 200 \mu \mathrm{M}$ P-EA, $1000 \mu \mathrm{M}$ MnSO $40.5 \mu \mathrm{M}$ BsAda, 4.72 $\mu \mathrm{M}$ SAHN and $0 \mu \mathrm{M}$ (red) or $2.5 \mu \mathrm{M}$ (black), of purified PfPMT enzyme in $100 \mathrm{mM}$ HEPES assay buffer pH 7.5. Reactions also contained $100 \mathrm{mM}$ HEPES assay buffer pH 7 (green), and pH 8 (cyan), as well as $100 \mathrm{mM}$ Tris- $\mathrm{HCl}$ assay buffer pH 7 (orange), pH 7.5 (purple), and pH 8 (yellow). Results are representative of three independent experiments. 
A

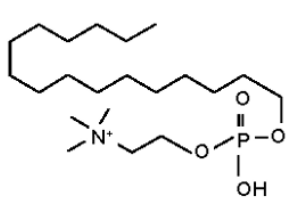

$\mathrm{HePC}$

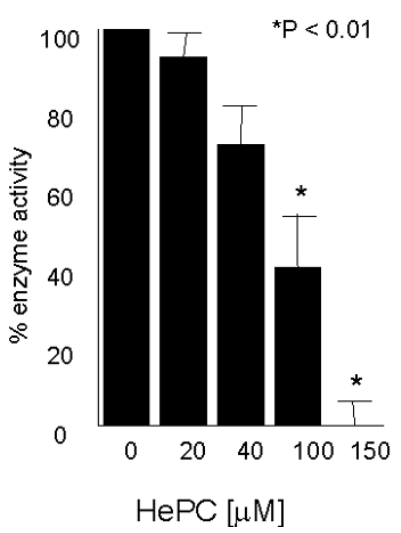

B<smiles>CCCCCCCCCCCCCCC[N+](C)(C)C</smiles>

HDTA

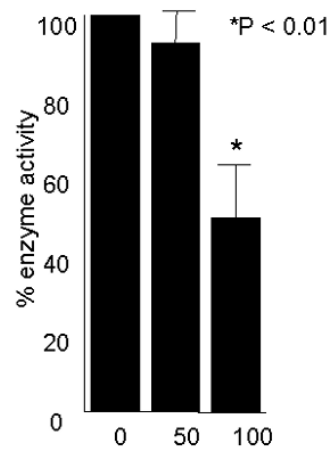

HDTA $[\mu \mathrm{M}]$
C

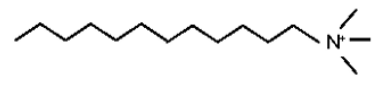

DDTA

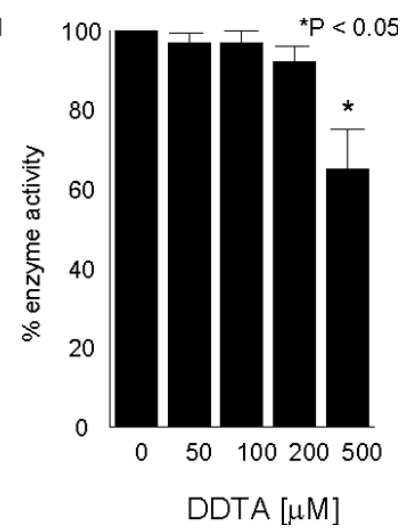

Figure 3 Inhibition of PfPMT by quaternary amines. Effect of increasing concentrations of hexadecylphosphocholine (HePC) (A), hexadecyltrimethylammonium bromide (HDTA) (B) and dodecyltrimethylammonium bromide (DDTA) on PfPMT activity. The assay was performed as described in Experimental Procedures. The data are the means +/- S.D. for three independent experiments. Statistically significant data with a $P<0.05$ is indicated with an asterisk.

dependent manner with $100 \mu \mathrm{M}$ drug reducing growth by $76 \%$ in medium containing $100 \mu \mathrm{M}$ ethanolamine after $60 \mathrm{~h}$ (Fig. 6B). These results thus demonstrate a direct inhibition of PfPMT by AQ in vivo. Addition of choline to the culture medium of pem1 1 pem $2 \Delta$-PfPMT cells resulted in complete resistance of these cells to AQ (Fig. 6E, curve $7 \& 8$ ), suggesting that the inhibition of growth was dependent on the essential function of PfPMT for survival in the absence of exogenous choline. As a control, the pem $1 \Delta$ pem $2 \Delta$ mutant harboring an empty vector did not grow in the absence of choline and was resistant to AQ when choline was added (Fig. 6D).

To demonstrate that the inhibition of the growth of pem $1 \Delta$ pem $2 \Delta+$ PfPMT by AQ was due to the inhibition of the synthesis of PtdCho from ethanolamine, the synthesis of the major phospholipids PtdCho and PtdEtn of yeast membranes was examined in the absence or presence of AQ. Consistent with previous findings [5,6], pem1 1 pem $2 \Delta$ cells harboring an empty vector produced $\sim 3 \%$ of total phospholipid as PtdCho after 5 to 6 generations of growth in the choline deficient medium, whereas those expressing PfPMT produced $\sim 18 \%$ PtdCho (Fig. 7). Addition of AQ to pem1 1 pem $2 \Delta$ cells expressing PfPMT resulted in a concentration dependent decrease in PtdCho levels with $\sim 15 \%$ produced at $10 \mu \mathrm{M}$ and $\sim 5 \%$ produced at $200 \mu \mathrm{M}$ AQ (Figs. 7A and $7 \mathrm{~B})$. These findings further demonstrate the specific inhibition of PtdCho biosynthesis by this compound.
The depletion of PtdCho effected by genetic manipulation or AQ treatment was partially compensated by increased levels of PtdIns (Fig. 7).

Structural analysis of the interaction between PfPMT and amodiaquine

Co-crystallization studies of human HNMT with AQ indicated that two molecules of AQ were bound per HNMT molecule [31]. One occupies the active site pocket (Site 1; Figs. 8A and $8 \mathrm{~B}$ ) and was proposed to competitively inhibit histamine binding, and the other occupies a deep pocket representing an uncompetitive component (Site 2; Figs. 8A and 8B) [31]. To characterize the nature of the inhibition of PfPMT by AQ and to calculate the inhibition constant, PfPMT activity was determined in the presence of increasing concentrations of P-EA and increasing concentrations of the inhibitor. These studies, however, did not allow distinction between competitive and noncompetitive inhibition. To further explore the interaction of AQ with PfPMT, we performed NMR studies of the enzyme with varying concentrations of AQ. The ${ }^{1} \mathrm{H}_{-}{ }^{15} \mathrm{~N}$ HSQC spectra revealed that of the 266 residues of PfPMT only about 20 residues showed a substantial change in chemical shift as a function of increasing concentrations of AQ (Fig. 9A and Additional file 1, Fig. S1). This demonstrates direct and site-specific binding of AQ to PfPMT. We were able to tentatively assign 9 of the 20 resonances exhibiting shifts upon AQ binding. Mapped onto corresponding residues in the HNMT structure (via 
A<smiles>CC(N)c1cccc(Cl)c1Cl</smiles>

DCMB

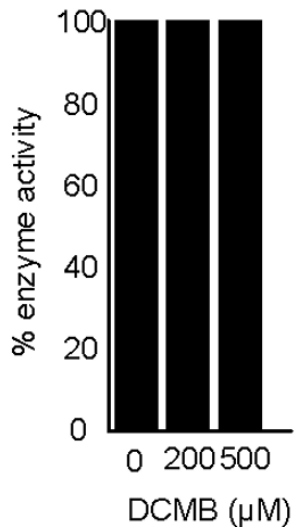

B<smiles>CCN(CC)Cc1cc(Nc2ccnc3cc(Cl)ccc23)ccc1O</smiles>

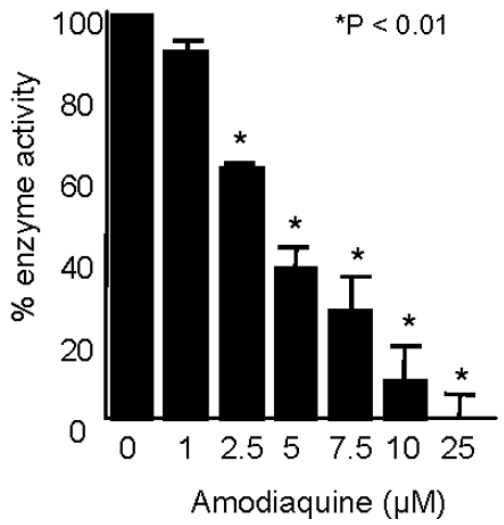

Figure 4 Amodiaquine inhibits purified PfPMT activity. Effect of increasing concentrations of DCMB (A) and amodiaquine (AQ) (B) on PfPMT activity. The assay was performed as described in Methods. The data are the means +/- S.D. for three independent experiments. Statistically significant data with a $P<0.01$ is indicated with an asterisk.

ClustalW sequence alignment), 8 of the 9 residues were found to be proximal to the two AQ binding sites in HNMT. The 9th residue is proximal to residues that are in contact with an AQ binding site. Nonspecific changes involving many residues that are observed at high AQ concentrations appear to reflect biophysical changes in solution properties due to a concentrated co-solute.

We also performed NMR titrations using CQ (Fig. 9B). While the effects of CQ are similarly restricted to about 20 residues, indicating site-specific binding, the affinity of CQ for PfPMT is much lower than that of AQ. Complete characterization of CQ binding by NMR is hampered by nonspecific effects that begin to dominate at concentrations above $3 \mathrm{mM}$ (molar ratio of 10 in Fig. 9). Detailed comparison of the concentration dependence of the chemical shifts for two residues, tentatively assigned to Gly32 and Gly68, revealed the difference in the affinities of AQ and CQ for PfPMT. For $A Q$, the chemical shift changes approached an asymptotic value approximately exponentially, consistent with all binding sites occupied around a 3:1 molar ratio (Figs. 9C and 9D). In contrast, the chemical shifts of Gly32 and Gly68 changed only linearly up to a molar ratio of 10:1. The fact that the same residues are perturbed in response to both AQ and CQ suggest that they interact with the same site on PfPMT, but the different concentration dependence suggests that the affinity of CQ for
PfPMT is at least an order of magnitude lower than that of $\mathrm{AQ}$.

\section{Discussion}

Methyltransferases represent a large group of enzymes divided into 160 classes (EC 2.1.1.1 to EC2.1.1.160). These enzymes catalyze the methylation of a large number of different substrates including DNA, RNAs, phospholipids, fatty acids, inositol, phosphoethanolamine, phenylethanolamine, tocopherol, catechol and histamine. Although some methyl donor molecules such as Smethylmethionine, betaine and folate can be used, the majority of biologically active methyltransferase enzymes utilize SAM as a methyl donor [32]. SAM-methyltransferases are recognized by the primary structure and topology of the core fold containing the SAM binding domain [32]. These enzymes play important functions in various biological systems and have been linked to different human diseases such as Alzheimer's disease, attention deficit disorder and pre-eclampsia [33-35]. Phosphoethanolamine methyltransferases (PMTs) represent a recently identified class of enzymes found mostly in plants, nematodes, frogs, fish and some species of protozoa. Their absence in humans and the finding that these enzymes play important physiological functions make them good targets for the development of novel inhibitors to treat worm and protozoan parasitic 


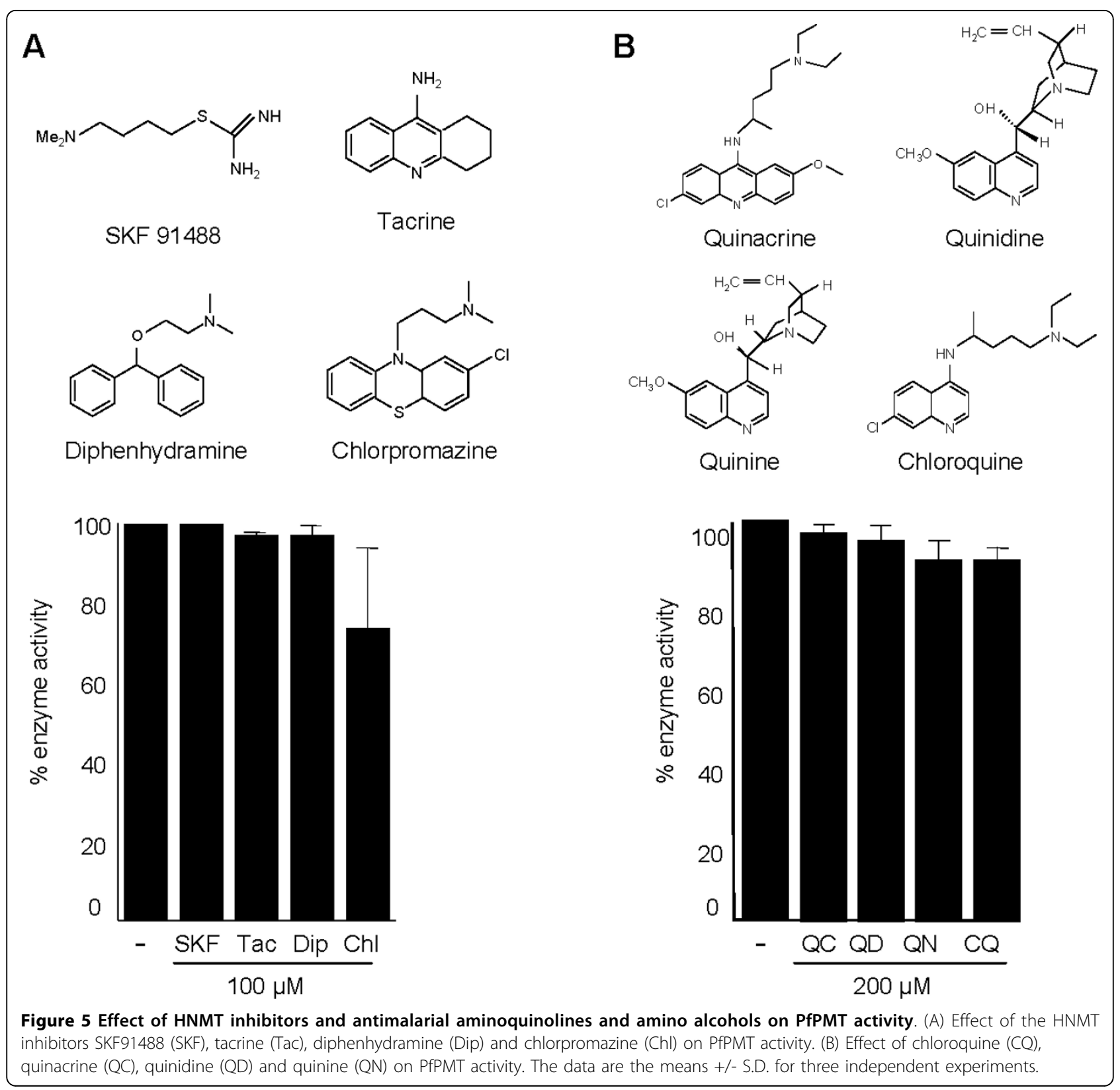

diseases $[3,8,11]$. The use of radiolabeled SAM to assay PMTs in vitro makes it difficult to perform large-scale screenings of available chemical libraries to search for inhibitors of these enzymes. Here we have modified a continuous coupled assay previously described by Dorgan et al [36] for the rat arginine N-methyltransferase 1 (PRMT1) to measure PfPMT activity in vitro and demonstrated its feasibility for drug inhibition assays using $\mathrm{HePC}$, which was previously shown to inhibit PfPMT with a radioactivity-based assay [3]. In this report, PfPMT activity was inhibited $\sim 60 \%$ at a concentration of $100 \mu \mathrm{M}$ of $\mathrm{HePC}$ and $150 \mu \mathrm{M}$ of this compound resulted in a complete loss of activity. The enzyme-coupled assay was also useful in identifying HDTA as an inhibitor of PfPMT activity. HDTA was found to have an inhibitory activity similar to that of HePC with $\sim 50 \%$ inhibition of PfPMT activity observed at $100 \mu \mathrm{M}$ of the compound. HDTA inhibits the growth of $P$. falciparum in culture with an $\mathrm{IC}_{50}$ of $2.1 \mu \mathrm{M}$ [24]. Using this assay we have also identified AQ as an inhibitor of PfPMT. In addition to its antimalarial activity, AQ is also known as a potent inhibitor of the human histamine N-methyltransferase (HNMT) [31]. Other more potent inhibitors of HNMT such as SKF91488, tacrine, 

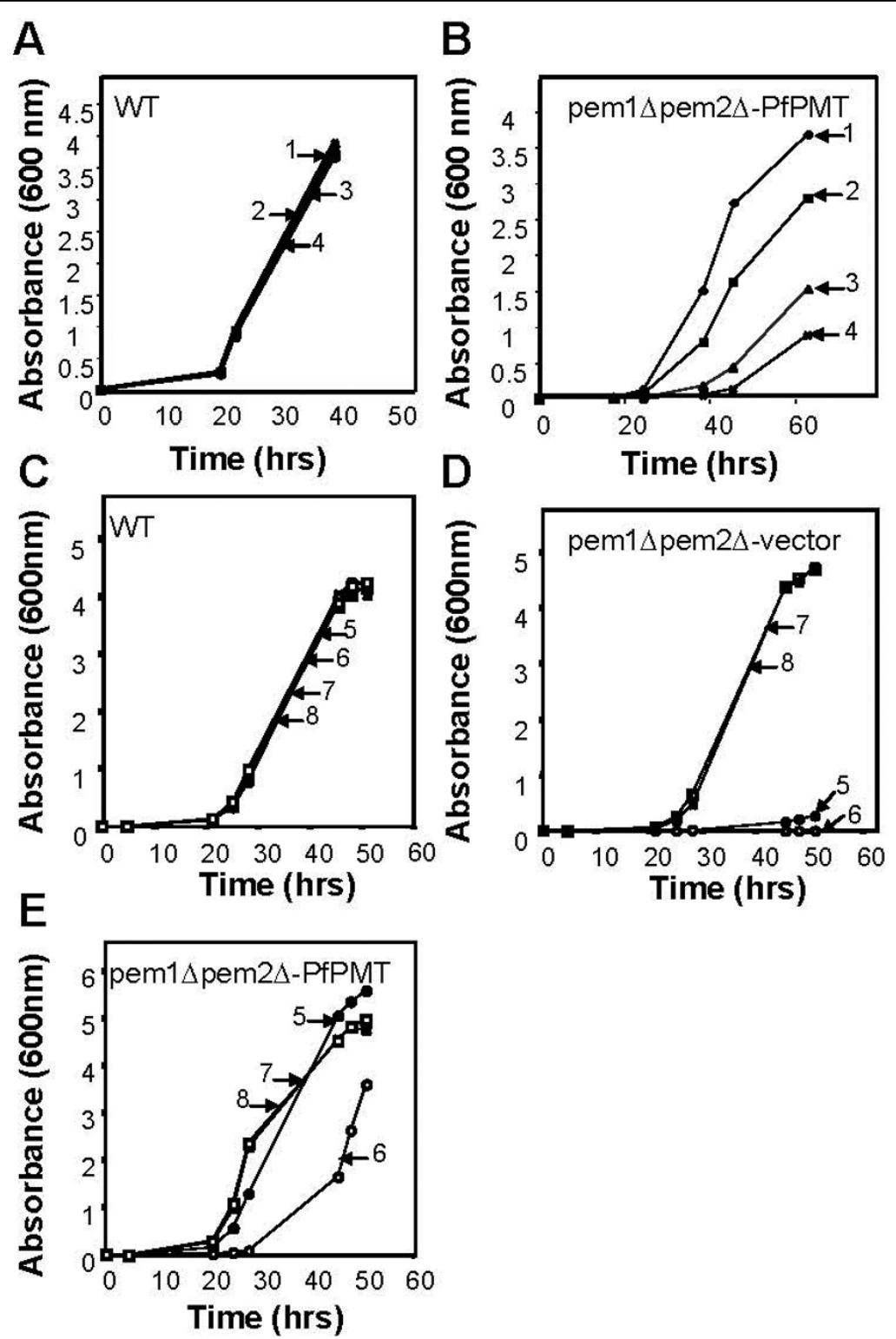

Figure 6 Amodiaquine inhibits PfPMT function in yeast. Growth curves of wild-type (BY4741-pYes2.1) (A) and pem14pem2A-PfPMT (B) strains grown in minimal medium containing $4 \%$ galactose and $100 \mu \mathrm{M}$ ethanolamine in the presence of $0 \mu \mathrm{M}(1), 10 \mu \mathrm{M}(2), 50 \mu \mathrm{M}(3)$, or 100 $\mu \mathrm{M}(4)$ AQ. (C-E) Growth curves of wild-type (BY4741-pYes2.1) (C), pem14pem2A-pYes2.1 (D) and pem14pem2A-PfPMT (E) yeast strains grown in minimal medium containing $4 \%$ galactose and $2 \mathrm{mM}$ ethanolamine in the presence of $0 \mu \mathrm{M} \mathrm{AQ}$ (5), $200 \mu \mathrm{M} \mathrm{AQ}(6), 200 \mu \mathrm{M} \mathrm{AQ}$ and $1 \mathrm{mM}$ choline (7), or $1 \mathrm{mM}$ choline (8).

diphenhydramine and chlorpromazine [37-39] had no effect on PfPMT, suggesting that the interaction between PfPMT and AQ is unique.

Amodiaquine is a structural analog of CQ. Analysis of uncomplicated falciparum malaria cases in Africa suggested that AQ is more effective in clearing parasites, including CQ resistant strains, and resulted in better clinical recovery compared to CQ [40-42]. Amodiaquine is used mostly in combination therapy with artesunate and sulfadoxine-pyrimethamine to treat malaria infections, especially those caused by CQ resistant strains [43]. Following oral administration, AQ is detected in the plasma between $30 \mathrm{~min}$ and $8 \mathrm{~h}$, but is rapidly converted to desethylamodiaquine (AQm) with a peak plasma concentration of $181 \pm 26 \mathrm{ng} \mathrm{ml}^{-1}$ [44]. In the liver $\mathrm{AQ}$ is converted to $\mathrm{AQm}$ by the polymorphic P450 isoform CYP2C8 [45]. Up to 96 hours after administration, AQm could be detected in the plasma, a property that made $\mathrm{AQ}$ an ideal compound in combination therapy [46]. In vitro both $\mathrm{AQ}$ and $\mathrm{AQm}$ inhibit parasite 


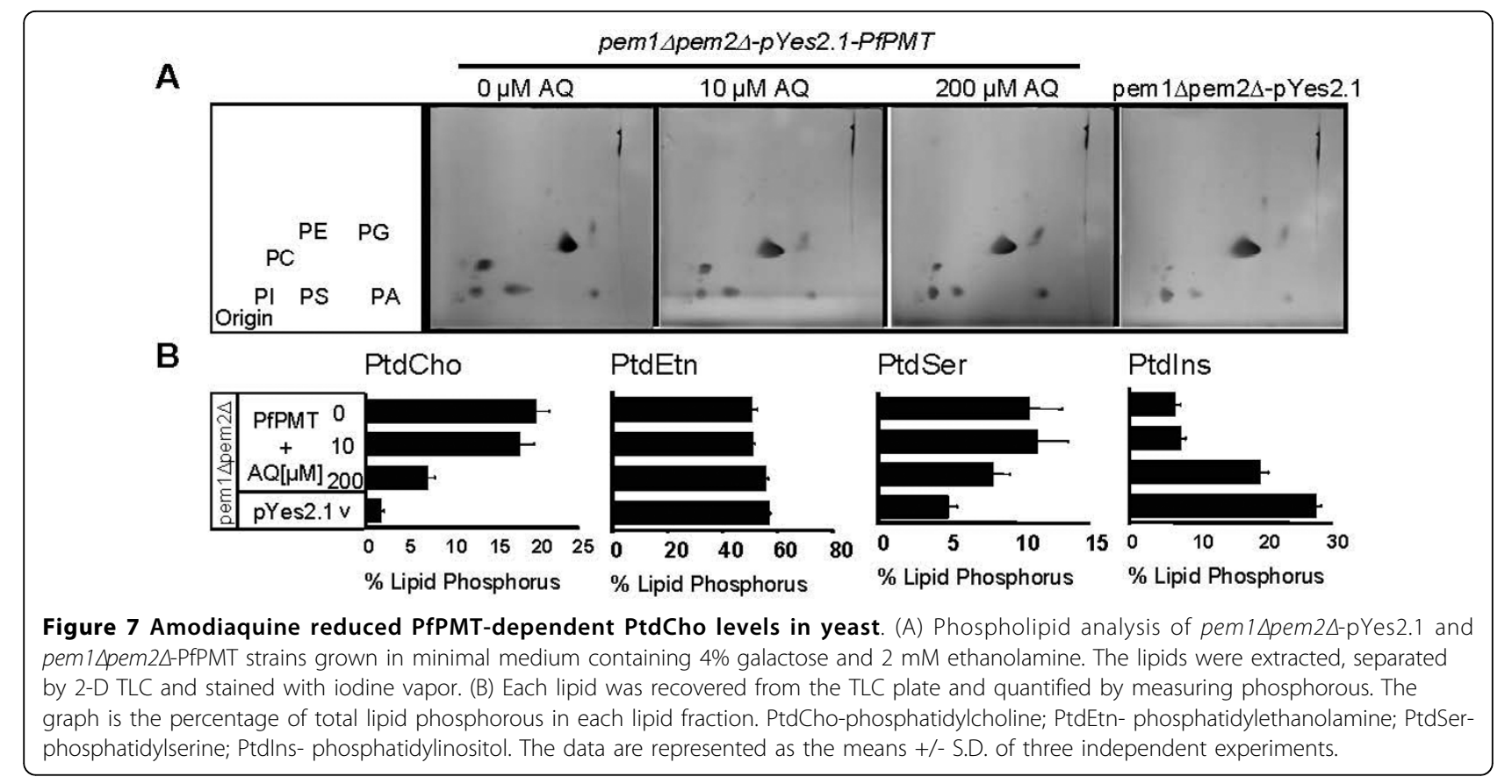

intraerythrocytic growth with $\mathrm{IC}_{50}$ values of 18.2 and $67.5 \mathrm{nM}$, respectively [47]. The modes of action of AQ and $\mathrm{AQm}$ are unknown. Field studies suggest that low levels of resistance to $A Q$ associate with mutations in the PfCRT and PfMDR1 genes, whereas high AQ resistance involves unknown mechanisms [48]. These findings suggest that AQ might have CQ like properties in the food vacuole as well as novel activities that remain to be elucidated. Interestingly, whereas AQ inhibited PfPMT activity, CQ did not. PfPMT activity was also not affected by the antimalarials quinine, quinidine and quinacrine at concentrations as high as $200 \mu \mathrm{M}$. The specificity of inhibition by AQ was demonstrated in vivo by using yeast as a surrogate system. In yeast, the growth of mutants that rely on PfPMT for survival was dramatically altered in the presence of this compound. Consistent with this phenotype, the synthesis of PtdCho in these complemented cells was strongly inhibited by AQ. Surprisingly, the amplitude of inhibition of pem1 $1 \Delta$ pem $2 \Delta+P f P M T$ cells by AQ was dependent on the
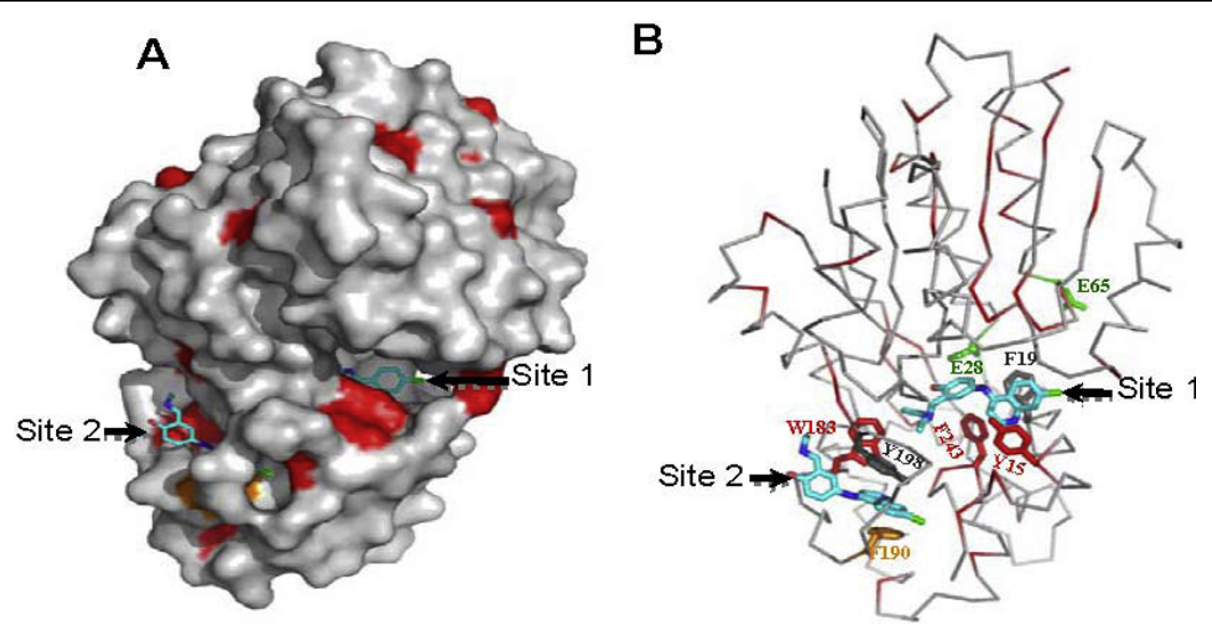

Figure 8 Prediction of amodiaquine-interacting residues on PfPMT using HNMT structure. (A) Molecular surface representation of HNMT. Red solvent-accessible surfaces identify invariant residues between HNMT and PfPMT. Phe190 is colored in orange. Two AQ molecules are shown as stick with the carbon atoms depicted in cyan, nitrogen in blue, oxygen in red, and chlorine in green. (B) The C $\alpha$ trace of HNMT in a similar orientation as (A). The AQ-interacting residues are shown as stick forms. The HNMT residues, corresponding to the nine residues of PfPMT whose chemical shifts are perturbed in response to AQ binding, are shown in green. Figures were prepared by using Pymol [56]. 


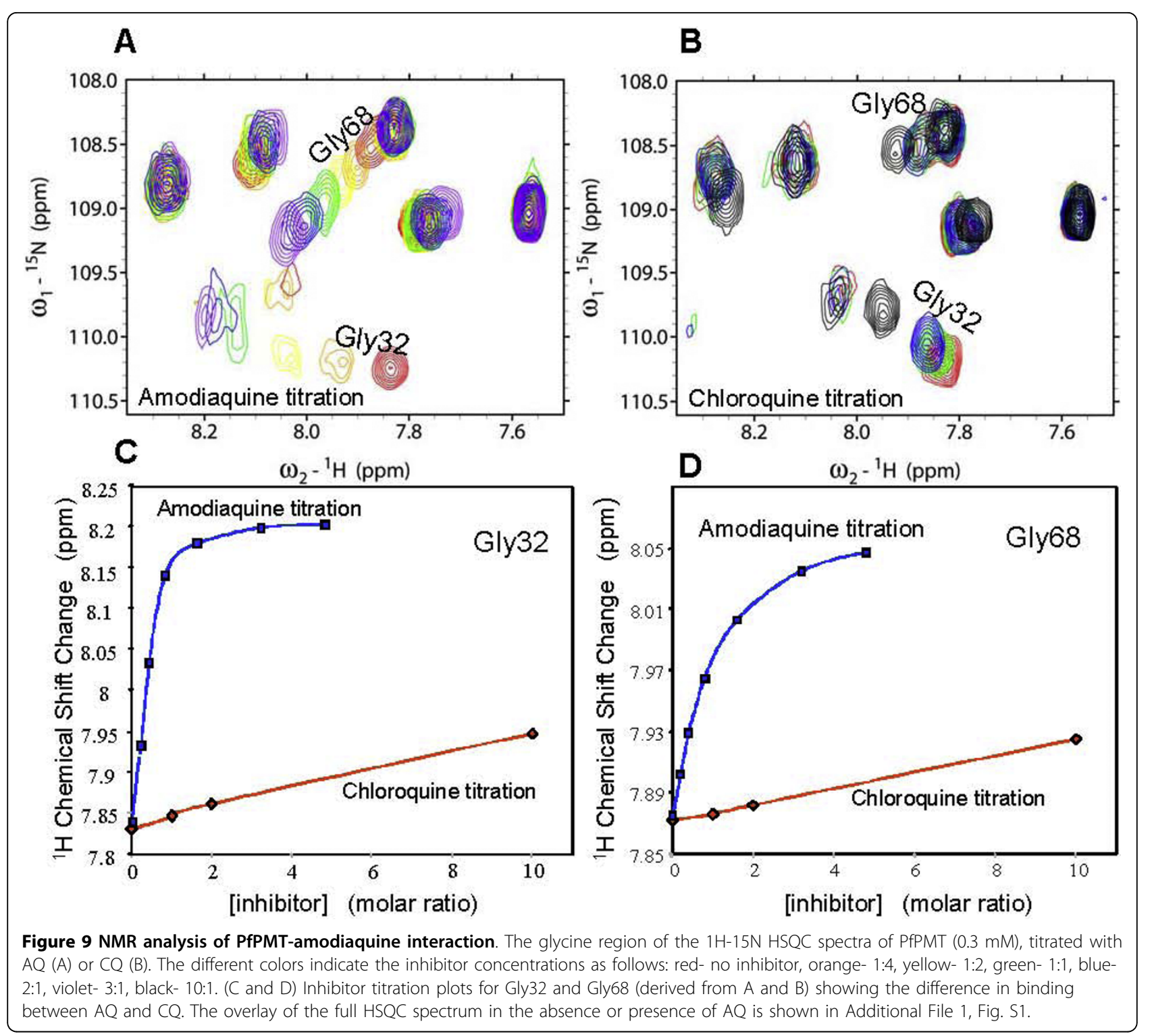

concentration of ethanolamine in the culture medium. This is likely due to the fact that these complemented cells grow faster on medium containing high concentrations of ethanolamine as a result of increased substrate availability for PfPMT.

Recent genetic studies have shown that PfPMT plays an important function during P. falciparum intraerythrocytic development, multiplication and survival [13], and an essential role in sexual differentiation (Bobenchik et al., unpublished data). Interestingly, silencing of the A. thaliana PEAMT results in multiple morphological phenotypes, including pale-green leaves, early senescence, temperature-sensitive male sterility and increased sensitivity to salts [49]. Furthermore, characterization of an $A$. thaliana mutant with the T-DNA inserted at the At3g18000 locus (XIPOTL1), which encodes PEAMT revealed severe alterations in root developmental and induces cell death in root epidermal cells [50]. In C. elegans, studies aimed at silencing the PEAMT genes $P M T-1$ and PMT-2 demonstrated an essential function of these genes in worm, growth, development and survival $[8,11]$. Altogether, these genetic studies validate PEAMT enzymes as possible targets for the development of inhibitors that could be used for the treatment of specific human and veterinary protozoa and nematode related infections as well as in agriculture.

$P$. falciparum parasites lacking PfPMT were, however, equally sensitive to $A Q$ as wild-type parasites in medium containing choline. This result suggests that PfPMT is not the sole target of AQ in choline-containing medium. Our finding that AQ inhibits PfPMT activity, and the fact that this compound also inhibits other eukaryotic 
methyltransferases, suggest that it may exert its antimalarial activity by targeting several parasite methyltransferases. Several studies have suggested that aminoquinolines may exert their antimalarial activity by interfering with biological functions other than heme detoxification in the digestive vacuole. Famin and Ginsburg reported inhibition of parasite's 6-phosphogluconate dehydrogenase by CQ [51]. Sharma and Mishra reported inhibition of parasite's tyrosine kinase by this compound [52]. Recently, CQ was reported to inhibit vesicular trafficking within the parasite [53], and to induce proteome oxidative damage [54]. More recent studies aimed at investigating the stage specificity of CQ and comparing the effect of continuous vs bolus dosing on $P$. falciparum strains revealed that rings (prior to the formation of the digestive vacuole) and schizont stage parasites (after hemoglobin degradation and heme detoxification activities have plateaued) were equally sensitive to this compound [55]. The bolus dosing concentrations of CQ used by Gligorijevic and colleagues are in the range of the compound's peak plasma concentration (low micromolar range) [55]. Together these studies suggest that heme detoxification, although important, is unlikely to be the only target of CQ. Although, the stage specificity and the effect of bolus dosing of AQ on P. falciparum have not been investigated, our results indicate that at its peak plasma concentration, AQ is likely to inhibit PfPMT and possibly other parasite methyltransferases. Future studies will aim to identify Plasmodium methyltransferases inhibited by AQ and to characterize the mechanism of sensitivity and resistance to AQ. From a chemistry standpoint, AQ represents an excellent lead compound for the rational design of better inhibitors of PfPMT and other parasite methyltransferases as well as plant and nematode PMTs.

Horton and coworkers have previously shown that AQ acts both as a competitive and a noncompetitive inhibitor of human HNMT [31]. The crystal structure of the HNMT-AQ complex [31] revealed that one AQ molecule binds to the histamine-binding site (Site 1), while the second one tucks into an adjacent pocket on the outer surface of the protein (Site 2) (Fig. 8A). Both quinoline rings fit into a sandwich-like structure formed by the aromatic side chains of Tyr15 and Phe19, and Phe190 and Tyr198, respectively (Fig. 8B). The side chains of Trp183 and Phe243 also contribute to the stabilization of the branched alkylamino tail of the AQ in the histamine-binding site [31]. It should be noted that the branch structure of the second AQ is disordered in the outer-surface pocket, suggesting a weaker binding interaction. The strong hydrophobic interactions between AQ and the aromatic side chains of the enzyme have been proposed to account for the affinity and specificity of the inhibitor for HNMT [31]. Sequence alignment analysis of HNMT and PfPMT shows that Tyr15, Trp183, and Phe243 are conserved in PfPMT, while Phe190 is substituted by tyrosine (Fig. 8B and Additional file 2, Fig. S2). This structural conservation is significant, as the two proteins have an overall $14 \%$ pairwise sequence identity. The majority of the other invariant residues are within the classic SAM-dependent methyltransferase fold in HNMT (Fig. 8B and Additional file 2, Fig. S2). Our inhibition studies revealed that whereas AQ inhibited PfPMT activity, CQ did not. PfPMT activity was also not affected by the aminoquinolines, quinine, quinidine and quinacrine at concentrations as high as $200 \mu \mathrm{M}$, or by the histamine methyltransferase inhibitors SKF91488, diphenhydramine and tacrine at concentrations as high as $100 \mu \mathrm{M}$. Unlike $A Q$, diphenhydramine and tacrine have been shown to interact only with Site 1 of HNMT. If this property is also valid in the case of PfPMT, it may account for the difference in inhibition of PfPMT activity between AQ and other aminoquinolines. The NMR studies reported here confirmed the site-specific binding of AQ to PfPMT, as less than $10 \%$ of residues in PfPMT showed a significant change in chemical shift in the presence of the compound. Nine of these residues have thus far been assigned. Six of those (corresponding to Glu28, Ser26, Ala63, Glu65, Ile66 and Met36 in HNMT) are proximal to the histamine-binding site (Site 1), while the 7th (Leu261 in HNMT) is proximal to Site 2. The 8th (Cys196 in HNMT) is located between the two sites. The last residue (Leu108 in HNMT) is further from Site 1 , but is proximal to residues in contact with this site, and could be a relayed effect. The three residues (Gly68, Gly32 and Gly40 corresponding to Glu65, Glu28 and Met36 in HNMT) with the largest shift changes are closest to site 1 . The binding of AQ to the free enzyme suggests that the inhibition is not uncompetitive, i.e. via binding to the enzyme-substrate complex, and therefore either competitive or noncompetitive. The NMR experiments at this stage do not definitively reveal whether AQ binds competitively to the substrate binding site. NMR studies to determine the structure of PfPMT alone and in combination with AQ are underway. They will address the question of noncompetitive vs. competitive inhibition, and should shed new light on the interaction between the enzyme and the inhibitor. However, based on our preliminary assignment of two of the nine assigned residues, Gly32 and Gly68, and the known structure of HNMT, we can postulate a structural hypothesis consistent with the NMR results for Gly32 and Gly68. Gly32 and Gly68 of PfPMT correspond to Glu28 and Glu65 of HNMT (Fig. 9). Glu28 lies at the bottom of the cleft comprising site 1 of HNMT. Glu65 also lines the surface of the cleft, closer to the enzyme surface. The similarity of the chemical shift perturbation 
curves (to within the experimental uncertainty of $0.006 \mathrm{ppm}$ ) for Gly32 and Gly68 is thus consistent with binding at site 1 . Despite the low sequence homology between PfPMT and HNMT, these data suggest that PfPMT and HNMT nevertheless exhibit structural homology, and are consistent with two AQ binding sites. The proximity of the two binding sites suggests that titration data might reflect coupling between sites. Indeed, we do not observe partitioning of the titration data into two distinct classes, as would be expected for independent binding sites.

\section{Conclusions}

The enzyme-coupled assay adapted for PfPMT is a simple and reliable method for measuring PfPMT activity and screening for specific inhibitors of this enzyme. The identification of $\mathrm{AQ}$ as an inhibitor of PfPMT may help in the future design of compounds that specifically inhibit this enzyme and possibly other PMTs.

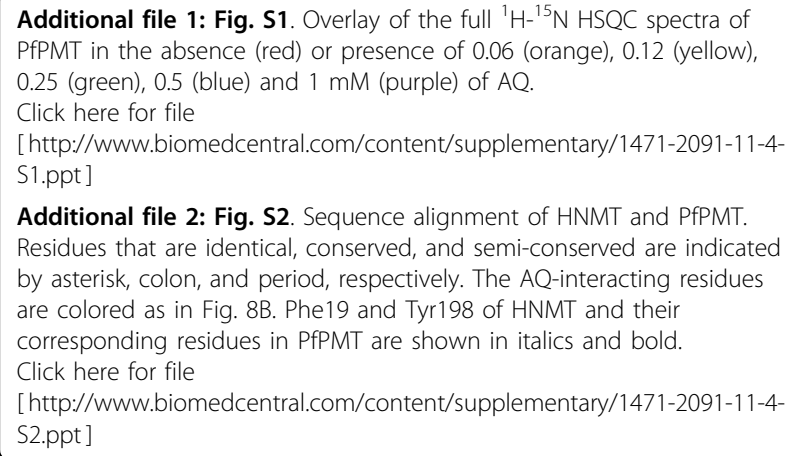

\section{Abbreviations}

AQ: amodiaquine AQm: desethylamodiaquine CQ: chloroquine PtdCho: phosphatidylcholine; PtdEtn: phosphatidylethanolamine; PtdSer: phosphatidylserine; P-EA: phosphoethanolamine; PMT: phosphoethanolamine methyltransferase; SDPM: serine decarboxylase phosphoethanolamine methyltransferase; CDP: citidylyldiphosphate; PfCCT: CDP-choline cytidylyltransferase; PfCEPT: CDP-diacylgylcerol-choline phosphotransferase; SAM: sadenosylmethionine; TLC: thin layer chromatography; SAH: sadenosylhomocystein; HNMT: histamine methyltransferase; NMR: nuclear magnetic resonance; SAHN: SAH nucleosidase.
\end{abstract}

\section{Acknowledgements}

We thank Dr. Peter Setlow for providing Bacillus subtilis DNA. We are grateful to Dr. Ken Cornell, Boise State University, for providing the SAH nucleosidase expression vector, and to Dr. Zhaohui Sunny Zhou, Washington State University, for helpful discussions about the assay. We thank Oksana Gorbatyuk, Li Luo and William Witola for help with the expression and purification of PfPMT. This research was supported by NIH and DOD grants [Al51507], [PR033005] and BWF award [1006267] to CBM. CBM is a recipient of the Burroughs Wellcome Award, Investigators of Pathogenesis of Infectious Disease. JCH acknowledges support from NIH [RR020125].

\section{Author details}

${ }^{1}$ Department of Internal Medicine, Section of Infectious Diseases, Yale School of Medicine, 333 Cedar St., New Haven, 06052, USA. ²Department of Genetics and Developmental Biology, University of Connecticut Health Center, 263 Farmington Ave., Farmington, 06030, USA. ${ }^{3}$ The Program in Cell
Biology, Department of Medicine, National Jewish Medical and Research

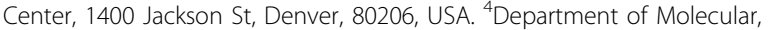
Microbial, and Structural Biology University of Connecticut Health Center, 263 Farmington Ave., Farmington, 06030, USA.

\section{Authors' contributions}

$A B$ optimized the enzyme coupled assay, performed the enzyme inhibitor studies, prepared all the figures and assisted in the writing and editing of the manuscript and the revisions. AM contributed to the initial development of the enzyme coupled assay and cloning of the BsADA used in the study. She also helped in the design of experiments and writing of the manuscript. JC and DV conducted the yeast growth assays and the yeast phospholipid analyses. IR, BH and JH contributed to the structural modeling and NMR analysis of PFPMT-amodiaquine interaction and helped in the writing and editing of the manuscript. CBM conceived, established the experimental framework of the study, analyzed the data and contributed to the writing and editing of the manuscript. All authors read and approved the final manuscript.

\section{Competing interests}

The authors declare that they have no competing interests.

Received: 28 July 2009

Accepted: 19 January 2010 Published: 19 January 2010

\section{References}

1. WHO: World Malaria Report 2008. Geneva: World Health Organisation 2008.

2. Pessi G, Ben Mamoun C: Pathways for phosphatidylcholine biosynthesis: targets and strategies for antimalarial drugs. Future Medicine, Future Lipidology 2006, 1(2):173-180.

3. Pessi $G$, Kociubinski G, Mamoun CB: A pathway for phosphatidylcholine biosynthesis in Plasmodium falciparum involving phosphoethanolamine methylation. Proc Natl Acad Sci USA 2004, 101:6206-6211.

4. Vial HJ, Ben Mamoun C, Sherman IW: Plasmodium lipids: Metabolism and Function. Molecular Approaches to Malaria Washington D.C.: ASM Press 2005, 327-352.

5. Pessi G, Choi JY, Reynolds JM, Voelker DR, Mamoun CB: In vivo evidence for the specificity of Plasmodium falciparum phosphoethanolamine methyltransferase and its coupling to the Kennedy pathway. $\mathrm{J} \mathrm{Biol} \mathrm{Chem}$ 2005, 280(13):12461-12466.

6. Reynolds JM, Takebe S, Choi JY, El Bissati K, Witola WH, Bobenchik AM, Hoch JC, Voelker DR, Mamoun CB: Biochemical and Genetic Analysis of the Phosphoethanolamine Methyltransferase of the Human Malaria Parasite Plasmodium falciparum. J Biol Chem 2008, 283(12):7894-7900.

7. Bolognese CP, McGraw P: The isolation and characterization in yeast of a gene for Arabidopsis S-adenosylmethionine:phospho-ethanolamine Nmethyltransferase. Plant Physiol 2000, 124(4):1800-1813.

8. Brendza KM, Haakenson W, Cahoon RE, Hicks LM, Palavalli LH, Chiapelli BJ, McLaird M, McCarter JP, Williams DJ, Hresko MC, et al: Phosphoethanolamine N-methyltransferase (PMT-1) catalyzes the first reaction of a new pathway for phosphocholine biosynthesis in Caenorhabditis elegans. Biochem J 2007, 404(3):439-448.

9. Charron JB, Breton G, Danyluk J, Muzac I, Ibrahim RK, Sarhan F: Molecular and biochemical characterization of a cold-regulated phosphoethanolamine N-methyltransferase from wheat. Plant Physiol 2002, 129(1):363-373

10. Nuccio ML, Ziemak MJ, Henry SA, Weretilnyk EA, Hanson AD: cDNA cloning of phosphoethanolamine $\mathrm{N}$-methyltransferase from spinach by complementation in Schizosaccharomyces pombe and characterization of the recombinant enzyme. J Biol Chem 2000, 275(19):14095-14101.

11. Palavalli LH, Brendza KM, Haakenson W, Cahoon RE, McLaird M, Hicks LM, McCarter JP, Williams DJ, Hresko MC, Jez JM: Defining the role of phosphomethylethanolamine N-methyltransferase from Caenorhabditis elegans in phosphocholine biosynthesis by biochemical and kinetic analysis. Biochemistry 2006, 45(19):6056-6065.

12. Witola WH, Pessi G, El Bissati K, Reynolds JM, Mamoun CB: Localization of the phosphoethanolamine methyltransferase of the human malaria parasite Plasmodium falciparum to the Golgi apparatus. J Biol Chem 2006, 281(30):21305-21311. 
13. Witola WH, El Bissati K, Pessi G, Xie C, Roepe PD, Mamoun CB: Disruption of the Plasmodium falciparum PfPMT gene results in a complete loss of phosphatidylcholine biosynthesis via the serine-decarboxylasephosphoethanolamine-methyltransferase pathway and severe growth and survival defects. J Biol Chem 2008, 283(41):27636-27643.

14. Lee JE, Cornell KA, Riscoe MK, Howell PL: Expression, purification, crystallization and preliminary X-ray analysis of Escherichia coli 5'methylthioadenosine/S-adenosylhomocysteine nucleosidase. Acta Crystallogr D Biol Crystallogr 2001, 57(Pt 1):150-152.

15. Matsui $H$, Shimaoka M, Kawasaki H, Takenaka Y, Kurahashi O: Adenine deaminase activity of the yicP gene product of Escherichia coli. BiosCi Biotechnol Biochem 2001, 65(5):1112-1118.

16. Bligh $E G$, Dyer WJ: A rapid method of total lipid extraction and purification. Can J Biochem Physiol 1959, 37(8):911-917.

17. Rouser G, Siakatose AN, Fleischer S: Quantitative analysis of phospholipids by thin layer chromatography and phosphorous analysis of spots. Lipids 1966, 1:85-86.

18. Viola G, Salvador A, Cecconet L, Basso G, Vedaldi D, Dall'Acqua F, Aloisi GG, Amelia M, Barbafina A, Latterini L, et al: Photophysical properties and photobiological behavior of amodiaquine, primaquine and chloroquine. Photochem Photobiol 2007, 83(6):1415-1427.

19. Edelhoch $\mathrm{H}$ : Spectroscopic determination of tryptophan and tyrosine in proteins. Biochemistry 1967, 6(7):1948-1954.

20. Gill SC, von Hippel PH: Calculation of protein extinction coefficients from amino acid sequence data. Anal Biochem 1989, 182(2):319-326

21. Pace CN, Vajdos F, Fee L, Grimsley G, Gray T: How to measure and predict the molar absorption coefficient of a protein. Protein Sci 1995, 4(11):2411-2423.

22. Delaglio F, Grzesiek S, Vuister GW, Zhu G, Pfeifer J, Bax A: NMRPipe: a multidimensional spectral processing system based on UNIX pipes. $J$ Biomol NMR 1995, 6(3):277-293.

23. Goddard TD, Kneller DG: University of California, San Franciscohttp://www. cgl.ucsf.edu/home/sparky/.

24. Ancelin ML, Calas M, Bompart J, Cordina G, Martin D, Ben Bari M, Jei T, Druilhe P, Vial HJ: Antimalarial activity of 77 phospholipid polar head analogs: close correlation between inhibition of phospholipid metabolism and in vitro Plasmodium falciparum growth. Blood 1998, 91(4):1426-1437

25. Ancelin ML, Calas M, Bonhoure A, Herbute S, Vial HJ: In vivo antimalarial activities of mono- and bis quaternary ammonium salts interfering with Plasmodium phospholipid metabolism. Antimicrob Agents Chemother 2003, 47(8):2598-2605.

26. Calas M, Cordina G, Bompart J, Ben Bari M, Jei T, Ancelin ML, Vial H: Antimalarial activity of molecules interfering with Plasmodium falciparum phospholipid metabolism. Structure-activity relationship analysis. J Med Chem 1997, 40(22):3557-3566.

27. Bondinell WE, Chapin FW, Frazee JS, Girard GR, Holden KG, Kaiser C, Maryanoff C, Perchonock CD, Gessner GW, Hieble JP, et al: Inhibitors of phenylethanolamine N-methyltransferase and epinephrine biosynthesis: a potential source of new drugs. Drug Metab Rev 1983, 14(4):709-721.

28. Olliaro P, Mussano P: Amodiaquine for treating malaria. Cochrane Database Syst Rev 2003, 2:CD000016.

29. Kodaki T, Yamashita S: Yeast phosphatidylethanolamine methylation pathway. Cloning and characterization of two distinct methyltransferase genes. J Biol Chem 1987, 262(32):15428-15435.

30. Summers EF, Letts VA, McGraw P, Henry SA: Saccharomyces cerevisiae cho2 mutants are deficient in phospholipid methylation and crosspathway regulation of inositol synthesis. Genetics 1988, 120(4):909-922

31. Horton JR, Sawada K, Nishibori M, Cheng X: Structural basis for inhibition of histamine N-methyltransferase by diverse drugs. J Mol Biol 2005, 353(2):334-344.

32. Fauman EB, Blumenthal RM, Cheng X: Structure and Evolution of AdoMetDependent Methyltransferases. S-adenosylmethionine-Dependent Methyltransferases: Structures and Functions Blumental XCaR: World Scientific 1998, 1-38.

33. Kanasaki K, Palmsten $K$, Sugimoto $H$, Ahmad S, Hamano $Y$, Xie L, Parry S, Augustin $\mathrm{HG}$, Gattone VH, Folkman J, et al: Deficiency in catechol-Omethyltransferase and 2-methoxyoestradiol is associated with preeclampsia. Nature 2008, 408(7198):1117-21.

34. Morisset S, Rouleau A, Ligneau X, Gbahou F, Tardivel-Lacombe J, Stark H, Schunack W, Ganellin CR, Schwartz JC, Arrang JM: High constitutive activity of native $\mathrm{H} 3$ receptors regulates histamine neurons in brain. Nature 2000, 408(6814):860-864.

35. Panula P, Rinne J, Kuokkanen K, Eriksson KS, Sallmen T, Kalimo H, Relja M: Neuronal histamine deficit in Alzheimer's disease. Neuroscience 1998, 82(4):993-997.

36. Dorgan KM, Wooderchak WL, Wynn DP, Karschner EL, Alfaro JF, Cui Y, Zhou ZS, Hevel JM: An enzyme-coupled continuous spectrophotometric assay for S-adenosylmethionine-dependent methyltransferases. Anal Biochem 2006, 350(2):249-255.

37. Malmberg-Aiello P, Lamberti C, Ipponi A, Hanninen J, Ghelardini C, Bartolini A: Effects of two histamine-N-methyltransferase inhibitors, SKF 91488 and BW $301 \mathrm{U}$, in rodent antinociception. Naunyn Schmiedebergs Arch Pharmacol 1997, 355(3):354-360.

38. Merril CR, Snyder SH, Bradley DF: Inhibition of histamine methyltransferase by serotonin and chlorpromazine derivatives: electronic aspects. Biochim Biophys Acta 1966, 118(2):316-324.

39. Taraschenko OD, Barnes WG, Herrick-Davis K, Yokoyama Y, Boyd DL, Hough LB: Actions of tacrine and galanthamine on histamine-Nmethyltransferase. Methods Find Exp Clin Pharmacol 2005, 27(3):161-165.

40. Brasseur P, Guiguemde R, Diallo S, Guiyedi V, Kombila M, Ringwald P, Olliaro P: Amodiaquine remains effective for treating uncomplicated malaria in west and central Africa. Trans R Soc Trop Med Hyg 1999, 93(6):645-650.

41. Fadat G, Le Bras J, Hengy C, Louis JP, Gimou MM, Verdier F: Efficacy of amodiaquine against chloroquine-resistant malaria in Cameroon. Lancet 1991, 338(8774):1092.

42. Olliaro P, Nevill C, LeBras J, Ringwald P, Mussano P, Garner P, Brasseur P: Systematic review of amodiaquine treatment in uncomplicated malaria. Lancet 1996, 348(9036):1196-1201.

43. Olliaro PL, Taylor WR: Antimalarial compounds: from bench to bedside. $J$ Exp Biol 2003, 206(Pt 21):3753-3759.

44. Winstanley $P$, Edwards $G$, Orme M, Breckenridge A: The disposition of amodiaquine in man after oral administration. Br J Clin Pharmacol 1987, 23(1):1-7.

45. Li XQ, Bjorkman A, Andersson TB, Ridderstrom M, Masimirembwa CM: Amodiaquine clearance and its metabolism to $\mathrm{N}$-desethylamodiaquine is mediated by CYP2C8: a new high affinity and turnover enzyme-specific probe substrate. J Pharmacol Exp Ther 2002, 300(2):399-407.

46. Churchill FC, Patchen LC, Campbell CC, Schwartz IK, Nguyen-Dinh P, Dickinson CM: Amodiaquine as a prodrug: importance of metabolite(s) in the antimalarial effect of amodiaquine in humans. Life Sci 1985, 36(1):53-62.

47. Childs GE, Boudreau EF, Milhous WK, Wimonwattratee T, Pooyindee N, Pang $L$, Davidson DE Jr: A comparison of the in vitro activities of amodiaquine and desethylamodiaquine against isolates of Plasmodium falciparum. Am J Trop Med Hyg 1989, 40(1):7-11.

48. Echeverry DF, Holmgren G, Murillo C, Higuita JC, Bjorkman A, Gil JP, Osorio L: Short report: polymorphisms in the pfcrt and pfmdr1 genes of Plasmodium falciparum and in vitro susceptibility to amodiaquine and desethylamodiaquine. Am J Trop Med Hyg 2007, 77(6):1034-1038.

49. Mou Z, Wang X, Fu Z, Dai Y, Han C, Ouyang J, Bao F, Hu Y, Li J: Silencing of phosphoethanolamine $\mathrm{N}$-methyltransferase results in temperaturesensitive male sterility and salt hepersensitivity in Arabidopsis. Plant Cell 2002, 4(9):2031-2043.

50. Cruz-Ramirez A, Lopez-Bucio J, Ramirez-Pimentel G, Zurita-Silva A, SanchezCalderon L, Ramirz-Chavez E, Gonzalez-Ortega E, Herrera-Estrella L: The xipotl mutant of Arabidopsis reveals a critical role for phospolipid metabolism in root system development and epidermal cell integrity. Plant Cell 2004, 16(8):2020-2034.

51. Famin $\mathrm{O}$, Ginsburg $\mathrm{H}$ : The treatment of Plasmodium falciparum-infected erythrocytes with chloroquine leads to accumulation of ferriprotoporphyrin IX bound to particular parasite proteins and to the inhibition of the parasite's 6-phosphogluconate dehydrogenase. Parasite 2003, 10(1):39-50.

52. Sharma A, Mishra NC: Inhibition of a protein tyrosine kinase activity in Plasmodium falciparum by chloroquine. Indian J Biochem Biophys 1999, 36(5):299-304

53. Roberts L, Egan TJ, Joiner KA, Hoppe HC: Differential effects of quinoline antimalarials on endocytosis in Plasmodium falciparum. Antimicrob Agents Chemother 2008, 52(5):1840-1842. 
54. Radfar A, Diez A, Bautista JM: Chloroquine mediates specific proteome oxidative damage across the erythrocytic cycle of resistant Plasmodium falciparum. Free Radic Biol Med 2008, 44(12):2034-2042.

55. Gligorijevic B, Purdy K, Elliott DA, Cooper RA, Roepe PD: Stage independent chloroquine resistance and chloroquine toxicity revealed via spinning disk confocal microscopy. Mol Biochem Parasitol 2008, 159(1):7-23.

56. Delano WL: The PyMOL User's Manual (2002). Delano Scientific. Palo Alto 2002.

doi:10.1186/1471-2091-11-4

Cite this article as: Bobenchik et al: Identification of inhibitors of

Plasmodium falciparum phosphoethanolamine methyltransferase using an enzyme-coupled transmethylation assay. BMC Biochemistry 2010 11:4.

Publish with Biomed Central and every scientist can read your work free of charge

"BioMed Central will be the most significant development for disseminating the results of biomedical research in our lifetime. "

Sir Paul Nurse, Cancer Research UK

Your research papers will be:

- available free of charge to the entire biomedical community

- peer reviewed and published immediately upon acceptance

- cited in PubMed and archived on PubMed Central

- yours - you keep the copyright 